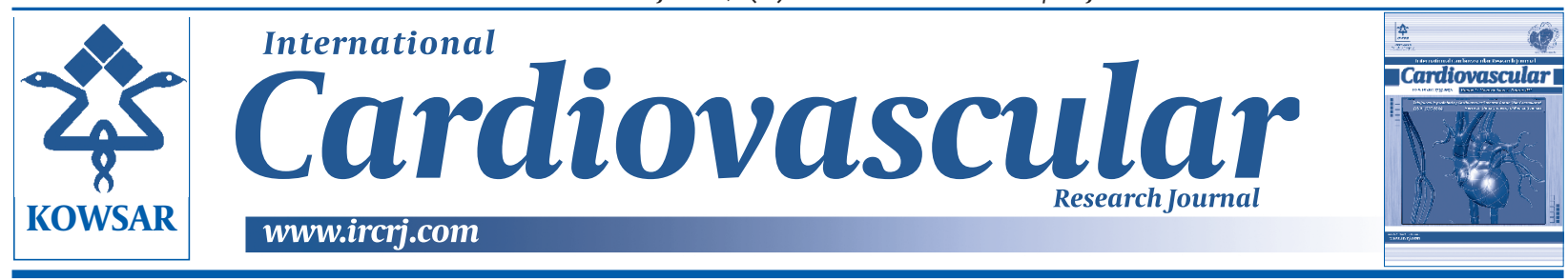

\title{
Cardiac Resynchronisation Therapy in Heart Failure
}

\author{
Arif Wahab ${ }^{1^{*}}$, Shaista Alvi ${ }^{2}$, Raja B. Panwar ${ }^{3}$, Sachin R. Gavade ${ }^{4}$ \\ ${ }^{1}$ Centre of Cardiology and Cardiovascular Sciences, Bikaner, Uttar Pradesh, India \\ ${ }^{2}$ Department of Internal Medicine, J.N.M.C.H, A.M.U, Aligarh, India \\ ${ }^{3}$ Centre of Cardiology and Cardiovascular Sciences, Bikaner, India \\ ${ }^{4}$ Department of Internal Medicine, P.B.M Hospital, Bikaner, India
}

\begin{tabular}{l}
\hline A R T I C L E I N F O \\
\hline Article type: \\
Review Article \\
\hline Article history: \\
Received: 12 Jul 2011 \\
Revised: 20 Jul 2011 \\
Accepted: 29 Jul 2011 \\
Keywords: \\
Preventive Cardiac Resynchronisa- \\
tion Therapy \\
Heart Failure \\
Auditory Neuropathy
\end{tabular}

\begin{abstract}
A B S T R A C T
Cardiac resynchronization therapy (CRT) represents one of the recent advances in heart failure (HF) management. It implies an attempt to establish left ventricular synchronous contraction in order to improve left ventricular hemodynamics; thereby improving functional class, and quality of life. CRT has come a long way from an incidental treatment modality to an accepted and indicated treatment strategy for patients suffering from severe and chronic heart failure. With its ever increasing use, it is important that we become conversant with its role in the management of heart failure. This article aims to review the evidence for CRT, how CRT benefits patients of heart failure and reveals the indications of CRT implantation in HF patients.
\end{abstract}

Auditory Neuropathy

Copyright @ 2011 Kowsar Corp. All rights reserved.

Implication for health policy/practice/research/medical education:

This review is intended for those managing patients of heart failure and aims to provide the recent advances and emerging role of CRT implantation in heart failure management.

Please cite this paper as:

Wahab A, Alvi S,Panwar RB, Gavade SR. Cardiac Resynchronisation Therapy in Heart Failure. Int Cardivasc Res J.2011;5(4):121-6 DOI: $10.5812 /$ icrj. 4653

\section{Introduction}

Heart failure (HF) is the final common end result of all forms of cardiac injury. Better and evidence-based management of patients, presenting with acute cardiac insult, has led to an increased burden of HF, as more and more patients with cardiac injury survive for longer duration of time, and add up to the pool of HF. Further addition to this epidemic pool is made by an increasing incidence of diabetes, hypertension, obesity and increased lifespan. Fortunately, management strategies for HF has also been continuously evolving starting from basic measures like lifestyle, modification to newer drug therapies and advanced interventions; like device ther-

* Corresponding author: Arif Wahab, Kashana-E-Wahab, Street No: 4, Iqra Colony, Near Iqra Public School, Aligarh, Uttar Pradesh, India. Tel: +918875884336, Fax: +91-1512226301, E-mail: drarifwahab@gmail.com

DOI: $10.5812 /$ icrj.4653

Copyright @2011 Kowsar Corp. All rights reserved. apy that has significantly contributed to the improved outlook for such patients. CRT represents one such device intervention indicated in patients with NYHA, Class III or ambulatory Class IV HF symptoms. It is not only reduces symptoms and incidence of hospital admission, but also significantly improves quality of life, functional status, exercise capacity, and left ventricular hemodynamics (1$4)$, that ultimately translates into a mortality benefit $(1,5)$.

\section{Intra-Ventricular Conduction Delay and Left Ventricular Dysfunction}

Left ventricular dysfunction in HF is associated with IVCD (Intra-ventricular conduction delay) in 15 to 30 percent (6-8) of cases, which usually manifests as bundlebranch block of LBBB morphology type $(3,4)$. In LBBB, the left ventricle is depolarized. Later than, right ventricle and activation of the anterior septum precedes inferior septal activation, the inferior and lateral aspects of the 
left ventricle are the last regions to get depolarized ( 9 , 10). Therefore, when depolarization spreads through LV, the septum and anterior LV are the first-to-contract while the lateral wall contraction is delayed. This results in pre-stretch of the lateral wall, delaying intracavitary pressure rise and mitral valve closure. Later on, when LV lateral free wall contracts the septum, and anterior LV is not synchronous, a corresponding stretch of the anteroseptal region is caused; thereby, aortic valve ejection is decreased. Dyssynchronous contraction creates mechanical inefficiency, with blood in heart partially getting pumped out of aorta and partially lying in the two dynamic intracavitary sinks (the stretched lateral wall in early systole, and the anteroseptal region in late systole). The delayed contraction of the postero-lateral LV wall and lateral papillary muscle promotes functional mitral regurgitation, by preventing the proper cooptation of the valve leaflets. Also, abnormal septal depolarization causes increasing in LV end-systolic diameter and decreasing in regional ejection fraction, decreasing cardiac output, mean arterial pressure, and $\mathrm{dP} / \mathrm{dt}$ (9, 11, 12). Delayed and prolonged depolarization in LBBB is associated with significantly later aortic valve closure and mitral opening, and delayed diastolic filling with concordant decrease in the duration of LV filling (9).

\section{Pathology}

Pathological changes are myriad ranging from a globally impaired ventricular function to an abnormally increased fiber strain, with concordant increase in metabolic activity, and tissue hypertrophy (13-15). Electrophysiological properties of these myocardial fibers are also deranged and reduced tissue refractoriness and conduction velocity is commonly found (16).

\section{Mechanism of CRT Benefit}

The exact mechanisms of CRT benefit are not known, but electrical synchronization can reduce the LBBB inducing, mechanical interventricular dyssynchrony between the right and left ventricle and intraventricular dyssynchrony within left ventricle. The beneficial effects of mechanical LV resynchronization appear to be independent of electrical synchrony.

\section{Acute Effect}

Mechanical benefits appear instantaneously after CRT implantation and include improving in $\mathrm{dP} / \mathrm{dtmax}$, aortic systolic pressure, and cardiac output (CO)(17). The PCWP declines and systolic pressure improves principally from an enhanced mechanical efficiency of LV (18-20). Elimination of early systolic lateral free wall stretch increases $\mathrm{CO}$, while late-systolic synchronous anteroseptal LV wall contraction causes an attendant decline in end systolic stress.

\section{Chronic Effects}

Chronic benefit includes reverse remodeling (21-25), improved LV function and decreased myocardial oxygen consumption (26). Long term bi-ventricular pacing is associated with a significant reduction in mitral regurgitation jet area $(4,27)$, left ventricular mass, left ventricular end-systolic and end-diastolic dimensions of all indicative reverse remodeling (28-30). MIRACLE and Vigor-CHF have reported approximately $10 \%$ of reductions in both end-systolic and end-diastolic volumes with 6-month CRT treatments $(29,30)$.The effect on chamber volume persists, even after cessation of CRT pacing suggested a remodeling effect rather than an active effect of CRT.

\section{Where to Pace; Bi -Ventricular or LV, Ante- rior or Free Wall?}

Though electrical synchrony and isovolumic relaxation rate is better with Bi-Ventricular CRT, (31-33) the mechanical effects are nearly the same with both types of CRT lead placement. Both modes increase $\mathrm{dP} / \mathrm{dtmax}, \mathrm{CO}$, and stroke volume to almost similar extent and independent of electrical effects (34). Butter et al. compared the acute effects of LV pacing site (anterior vs. free wall) on net change in global systolic function. He found that LV free wall pacing consistently resulted in greater increases in $\mathrm{dP} / \mathrm{dtmax}$ and aortic pulse pressure than did anterior pacing (35). Accordingly, CS pacing leads are typically placed in midlateral wall positions, frequently over a guideword directed into the selected tributary3.In a study by Gasparini et al. the effects of differential pacing sites were evaluated in CRT treated patients, the results were not in favor of lateral wall pacing. Separated from the stimulation site, the clinical and echocardiographic parameters were significantly improved in the most of the patients (36). Thereby, the pacing of an alternate site when leading a lateral wall placement is not technically feasible.

\section{Major Trial Evidence for CRT}

MUSTIC: This trial was divided into two groups based on their basic rhythms $(2,37)$. Group one (MUSTIC SR) included 67 patients with NYHA class III heart failure, QRS duration $>150 \mathrm{~ms}$ with stable sinus rhythm and no conventional indications for pacemaker therapy (2). The patients were randomly assigned to BiV pacing, or no BiV pacing for three months after which the pacing modes were switched. Significant improvement was seen with exercise tolerance, quality of life, peak oxygen consumption, with a two-thirds reduction in rate of hospital admission. The benefits with BiV pacing compared to baseline were maintained at 12 months (37). Group two MUSTIC - AF included 59 patients with heart failure and chronic AF (atrial fibrillation) with a wide QRS complex that required a permanent pacemaker, because of a slow ventricular rate. These patients were randomly assigned to either single site RV pacing or BiV pacing for three 
months and later the pacing modes were switched (37). Benefits were similar to the MUSTIC - SR group, though fewer patients eventually completed this study arm.

\section{MIRACLE}

First Randomized double blind trial evaluated the morbidity benefits of CRT on patients with NYHA Class III and IV symptoms and LV dysfunction (LVEF $<35 \%$ and a QRS duration $>130 \mathrm{~ms}$ ). Compared with the control group, patients randomized to cardiac resynchronization demonstrated a significant improvement in quality of life score, 6-minute walk distance, NYHA functional class, treadmill exercise time, peak $\mathrm{O} 2$ consumption and LVEF (29). The benefits shown by this trial lead FDA to approve CRT as a treatment modality for CHF.

\section{CARE-HF}

Open labeled RCT evaluated mortality benefit in patients on optimized medical therapy (OMT) with CRT $v s$. OMT alone (38). Enrolled patients were in NYHA class III or IV systolic heart failure and had evidence of ventricular dyssynchrony (QRS duration > $150 \mathrm{~ms}$, or QRS duration between 120 - $150 \mathrm{~ms}$ plus echocardiographic evidence of dyssynchrony). At a mean of 29-month follow up CRT reduced both the primary-end point and the secondaryend point of all-cause death by approximately $36 \%$, and the survival curves continued to separate thereafter.

\section{PATH CHF}

Patients with CRT (Bi-V or LV) had significant improvement on peak $\mathrm{O} 2$ consumption, 6-min walk test and NYHA class (39).

\section{CRT With ICD: Trials}

COMPANION Study (40): Open-labeled randomize-controlled trial that enrolled 1,520 patients in a 1:2:2 fashion to OMT, CRT, and CRT-D therapy. The criteria for inclusion had in addition to NYHA Class III or IV and QRS $>150 \mathrm{~ms}$ an episode of hospitalization for HF in the year preceding to randomization. The primary-end point was the composite of death or hospitalization from any cause; secondary-end points included death from any cause. The trial was prematurely discontinued in Nov 2002, due to the significant benefit seen in the device group. Compared with control patients (group 1), the primaryend point was significantly reduced in device group in comparison to the medical controls (18.6\% in CRT and by 19.3 \% in CRT-D group, $P<0.015$ and 0.005 , respectively). All-cause mortality was reduced significantly only in CRT-D group ( $43 \%$ reduction, $P=0.002$ ) when compared to the controls, the CRT group showed a strong trend towards mortality benefit that did not reach statistical significance (reduction by $24 \%, P=0.12$ ). The study was underpowered to compare mortality benefit between the device groups. The result of this trial paved the way for the use of CRT-D in above subset of patients.

\section{MIRACLE-ICD}

Prospective randomized controlled trial that enrolled 369 patients with NYHA class 3 or $4 \mathrm{HF}, \mathrm{LVEF}<35 \%$, and a wide QRS interval ( $>130$ milliseconds), to either the active treatment arm with CRT (CRT on, ICD on; $n=187$ ), or to the control group (CRT off, ICD on; $n=182$ ) and followed for 6 months for a composite endpoint of mortality, hospitalization and symptomatic improvement (41). At six months, patients assigned to CRT therapy had a greater improvement in median quality-of-life score, functional class and exercise capacity than the control group, but there were no differences in the six-minute walk test or arrhythmic events. Therefore, the combination of CRT with ICD was considered to be safe and effective in patients requiring both devices.

\section{Current Indications}

According to the recent updated guidelines of the American Heart Association, implantation of CRT is a class I recommendation in patients with $\mathrm{EF}<35 \%$, class III or ambulatory class IV heart failure; despite maximal medical therapy, QRS more than $120 \mathrm{~ms}$, and who are in sinus rhythm (Level of evidence A) $(42,43)$. In addition, CRT is considered reasonable (Class IIa) for patients with LVEF $\leq 35$ percent with NYHA functional class III, or ambulatory class IV symptoms who are receiving OMT and who have frequent dependence on ventricular pacing or are in atrial fibrillation (42). Consideration for CRT implantation (Class IIb) may be given to patients with LVEF $\leq 35$ percent with NYHA functional class I or II symptoms, who are receiving optimal recommended medical therapy and who are undergoing implantation of a permanent pacemaker and / or ICD with anticipated frequent ventricular pacing (42). The appropriateness of CRT for patients in marked dyssynchrony and class I or II HF, patients with HF and sustained RV apical pacing, and patients with end-stage CHF are recognized as unresolved issues (43).

\section{Implantation Technique}

The CRT device is implanted by venous approach, using fluoroscopic guidance to place pacing lead through the cephalic, axillary, or subclavian veins into the right atrium, right ventricle, and a tributary of the (coronary sinus). CS venography using an occlusive balloon tipped catheter is done at the time of LV lead implantation, in order to select the most appropriate lateral vein for LV pacing (44). Whether to approach the vein from right or left side depends on the operator's practice and the layout of the laboratory; however, if the CRT device is implanted includes cardio version / defibrillation functions, the left side is preferred, since the average defibrillation energy requirements are lower from the left side due to better electrical vectors. Following LV leads to the placement of the position which is confirmed by fluoroscopy in left anterior oblique view. LV leads in base to mid-posterolateral position with maximum LV-RV lead separation indicates 
a good position. The pacing and sensing parameters are checked and diaphragmatic stimulation ruled out by high voltage pacing.Pacing thresholds are acceptable if they are less than $3 \mathrm{~V}$ at 0.5 milliseconds. Finally, the CRT device is connected to the leads and site closed.

\section{Programming for Optimization}

Usually in CRT device the RV lead is bipolar with distal stimulating cathode and a proximal non-stimulating anode, while the LV lead has a distal stimulating unipolar cathode. Modification of the AV and VV delay is required for optimal cardiac synchrony during sequential atrioventricular pacing. This can be done by:

- Aortic VTI (velocity time integral) method: Aortic VTI is directly proportional to the stroke volume and AV delay is so timed, so that VTI is maximum.

- Mitral inflow method: Shortest AV delay that allows for separation of E and A wave with the end of A wave coinciding with the closure of mitral valve.

- Left Ventricular dP/dt method: AV delay is optimized for a maximum rate of pressure change in left ventricle.

Aurrichio et al.; however, demonstrated that comparable mechanical benefits are achieved across a moderate range of AV delays (19). Thus, while some patients with particularly long intrinsic delays require customization, most will gain a similar CRT effect by using a nominal delay of around $120 \mathrm{~ms}$.

With the use of newer CRT devices optimal VV delay, customerisation is also required. This is done by selecting the V-V delay that maximizes the VTI across the aortic valve. Sogard et al reported that LV ejection fraction improves by about $8 \%$ by V-V delay optimization with LV dyssynchrony, showing an improvement after implantation (45). In the recent nSync III Marquis trial, though the primary endpoint of clinical composite response at 6 months did not significantly differ between CRT-D and CRT-D + V-V groups $(P<0.001)$, the investigators noted a small trend toward improvement in patients with CRT-D $+\mathrm{V}-\mathrm{V}$ patients (46).

\section{Pitfalls and Complications of CRT Ther- apy}

CRT implantation is a technically challenging procedure. Most studies have found failure rate of 8-12 \% (47, 48), majority being due to failed LV lead implantation (6 $\%$ according to MacAllister55). Mortality during the procedure averages $0.4-1$ percent $(49,50)$ and device-related complications, during the first 6 months included lead malfunction or dislodgement (8.5\%), device malfunction (6.7\%), arrhythmia attributable to CRT (2\%), and site infection $(1.4 \%)(5,48)$. The complication rates are generally higher when implantation is done by a non-electrophysiologist (51).

\section{Conclusion}

CRT represents one of the recent additions to the growing armamentarium of HF therapy and with an increas- ing body of evidence, showing mortality advantages in patients with CRT devices. It may be not far off that this therapy finds an ever growing indication for use and compete with drug therapy; as the primary modality of treating incipient or manifest heart failure.

\section{Acknowledgments}

There is no acknowledgment.

\section{Financial Disclosure}

There is no financial disclosure.

\section{Funding/Support}

There is no funding/support.

\section{References}

1. Abraham WT, Fisher WG, Smith AL, Delurgio DB, Leon AR, Loh E, et al. Cardiac resynchronization in chronic heart failure. $\mathrm{N} \mathrm{Engl} \mathrm{J}$ Med. 2002;346(24):1845-53.

2. Cazeau S, Leclercq C, Lavergne T, Walker S, Varma C, Linde C, et al. Effects of multisite biventricular pacing in patients with heart failure and intraventricular conduction delay. N Engl J Med. 2001;344(12):873-80.

3. Sogaard P, Egeblad H, Kim WY, Jensen HK, Pedersen AK, Kristensen BO, et al. Tissue Doppler imaging predicts improved systolic performance and reversed left ventricular remodeling during long-term cardiac resynchronization therapy. J Am Coll Cardiol. 2002;40(4):723-30.

4. St John Sutton MG, Plappert T, Abraham WT, Smith AL, DeLurgio DB, Leon AR, et al. Effect of cardiac resynchronization therapy on left ventricular size and function in chronic heart failure. Circulation. 2003;107(15):1985-90.

5. McAlister FA, Ezekowitz JA, Wiebe N, Rowe B, Spooner C, Crumley E, et al. Systematic review: cardiac resynchronization in patients with symptomatic heart failure. Ann Intern Med. 2004;141(5):381-90.

6. Shamim W, Francis DP, Yousufuddin M, Varney S, Pieopli MF, Anker SD, et al. Intraventricular conduction delay: a prognostic marker in chronic heart failure. Int J Cardiol. 1999;70(2):171-8.

7. Baldasseroni S, Opasich C, Gorini M, Lucci D, Marchionni N, Marini M, et al. Left bundle-branch block is associated with increased 1-year sudden and total mortality rate in 5517 outpatients with congestive heart failure: a report from the Italian network on congestive heart failure. Am Heart J. 2002;143(3):398-405.

8. Werling C, Weisse U, Siemon G, Kiessling AH, Rameken M, Schwacke $\mathrm{H}$, et al. Biventricular pacing in patients with ICD: how many patients are possible candidates? Thorac Cardiovasc Surg. 2002;50(2):67-70.

9. Grines CL, Bashore TM, Boudoulas H, Olson S, Shafer P, Wooley CF. Functional abnormalities in isolated left bundle branch block. The effect of interventricular asynchrony. Circulation. 1989;79(4):845-53.

10. Wyndham CR, Smith T, Meeran MK, Mammana R, Levitsky S, Rosen KM. Epicardial activation in patients with left bundle branch block. Circulation.1980;61(4):696-703.

11. Takeshita A, Basta LL, Kioschos JM. Effect of intermittent left bundle branch block on left ventricular performance. Am J Med. 1974;56(2):251-5.

12. Bramlet DA, Morris KG, Coleman RE, Albert D, Cobb FR. Effect of rate-dependent left bundle branch block on global and regional left ventricular function. Circulation. 1983;67(5):1059-65.

13. McVeigh ER, Prinzen FW, Wyman BT, Tsitlik JE, Halperin HR, Hunter WC. Imaging asynchronous mechanical activation of the paced heart with tagged MRI. Magn Reson Med.1998;39(4):507-13.

14. van Oosterhout MF, Prinzen FW, Arts T, Schreuder JJ, Vanagt WY, Cleutjens JP, et al. Asynchronous electrical activation induces asymmetrical hypertrophy of the left ventricular wall. Circulation. 1998;98(6):588-95.

15. van Oosterhout MF, Arts T, Bassingthwaighte JB, Reneman RS, 
Prinzen FW. Relation between local myocardial growth and blood flow during chronic ventricular pacing. Cardiovasc Res. 2002;53(4):831-40.

16. Spragg DD, Akar FG, Helm RH, Tunin RS, Tomaselli GF, Kass DA. Abnormal conduction and repolarization in late-activated myocardium of dyssynchronously contracting hearts. Cardiovasc Res. 2005;67(1):77-86.

17. Kass DA. Ventricular dyssynchrony and mechanisms of resynchronization therapy. Eur Heart J. 2002;4(suppl D):D23-D30.

18. Blanc JJ, Etienne Y, Gilard M, Mansourati J, Munier S, Boschat J, et al. Evaluation of different ventricular pacing sites in patients with severe heart failure: results of an acute hemodynamic study. Circulation. 1997;96(10):3273-7.

19. Auricchio A, Stellbrink C, Block M, Sack S, Vogt J, Bakker P, et al. Effect of pacing chamber and atrioventricular delay on acute systolic function of paced patients with congestive heart failure. The Pacing Therapies for Congestive Heart Failure Study Group. The Guidant Congestive Heart Failure Research Group. Circulation. 1999;99(23):2993-3001.

20. Kass DA, Chen CH, Curry C, Talbot M, Berger R, Fetics B, et al. Improved left ventricular mechanics from acute VDD pacing in patients with dilated cardiomyopathy and ventricular conduction delay. Circulation.1999;99(12):1567-73.

21. Yu CM, Chau E, Sanderson JE, Fan K, Tang MO, Fung WH, et al. Tissue Doppler echocardiographic evidence of reverse remodeling and improved synchronicity by simultaneously delaying regional contraction after biventricular pacing therapy in heart failure. Circulation. 2002;105(4):438-45.

22. Duncan A, Wait D, Gibson D, Daubert JC. Left ventricular remodelling and haemodynamic effects of multisite biventricular pacing in patients with left ventricular systolic dysfunction and activation disturbances in sinus rhythm: sub-study of the MUSTIC (Multisite Stimulationin Cardiomyopathies) trial. Eur Heart J. 2003;24(5):430-41.

23. Gras D, Leclercq C, Tang AS, Bucknall C, Luttikhuis HO, KirsteinPedersen A. Cardiac resynchronization therapy in advanced heart failure the multicenter InSync clinical study. Eur J Heart Fail. 2002;4(3):311-20.

24. Auricchio A, Stellbrink C, Butter C, Sack S, Vogt J, Misier AR, et al. Clinical efficacy of cardiac resynchronization therapy using left ventricular pacing in heart failure patients stratified by severity of ventricular conduction delay.J Am Coll Cardiol.2003;42(12):2109-16.

25. Blanc JJ, Bertault-Valls V, Fatemi M, Gilard M, Pennec PY, Etienne Y. Midterm benefits of left univentricular pacing in patients with congestive heart failure. Circulation. 2004;109(14):1741-4.

26. Nelson GS, Berger RD, Fetics BJ, Talbot M, Spinelli JC, Hare JM, et al. Left ventricular or biventricular pacing improves cardiac function at diminished energy cost in patients with dilated cardiomyopathy and left bundle-branch block. Circulation. 2000;102(25):3053-9.

27. Breithardt OA, Sinha AM, Schwammenthal E, Bidaoui N, Markus KU, Franke A, et al. Acute effects of cardiac resynchronization therapy on functional mitral regurgitation in advanced systolic heart failure. $J$ Am Coll Cardiol. 2003;41(5):765-70.

28. Saxon LA, De Marco T, Schafer J, Chatterjee K, Kumar UN, Foster E. Effects of long-term biventricular stimulation for resynchronization on echocardiographic measures of remodeling. Circulation. 2002;105(11):1304-10.

29. Abraham WT. Data from Multicenter InSync Randomized Clinical Evaluation (MIRACLE) presented at the American College of Cardiology 50th Annual Scientific Session. Orlando,Florida: American Heart Assiciate; 2001 [updated 2001; cited]; Available from: http:/ circ.ahajournals.org/content/103/14/e9030.full.

30. Stellbrink C, Breithardt OA, Franke A, Sack S, Bakker P, Auricchio A, et al. Impact of cardiac resynchronization therapy using hemodynamically optimized pacing on left ventricular remodeling in patients with congestive heart failure and ventricular conduction disturbances. J Am Coll Cardiol. 2001;38(7):1957-65.

31. Hay I, Melenovsky V, Fetics BJ, Judge DP, Kramer A, Spinelli J, et al. Short-term effects of right-left heart sequential cardiac resynchronization in patients with heart failure, chronic atrial fibrillation, and atrioventricular nodal block. Circulation. 2004;110(22):3404-10.

32. Bordachar P, Lafitte S, Reuter S, Garrigue S, Sanders P, Roudaut R, et $a l$. Biventricular pacing and left ventricular pacing in heart failure: similar hemodynamic improvement despite marked electrome- chanical differences. J Cardiovasc Electrophysiol. 2004;15(12):1342-7.

33. Kass D. Left ventricular versus biventricular pacing in cardiac resynchronization therapy: the plot in this tale of two modes.J Cardiovasc Electrophysiol.2004;15(12):1348-9.

34. Leclercq C, Faris O, Tunin R, Johnson J, Kato R, Evans F, et al. Systolic improvement and mechanical resynchronization does not require electrical synchrony in the dilated failing heart with left bundlebranch block. Circulation. 2002;106(14):1760-3.

35. Butter C, Auricchio A, Stellbrink C, Fleck E, Ding J, Yu Y, et al. Effect of resynchronization therapy stimulation site on the systolic function of heart failure patients. Circulation. 2001;104(25):3026-9.

36. Gasparini M, Mantica M, Galimberti P, Bocciolone M, Genovese L, Mangiavacchi M, et al. Is the left ventricular lateral wall the best lead implantation site for cardiac resynchronization therapy? Pacing Clin Electrophysiol. 2003;26(1 Pt 2):162-8.

37. Linde C, Leclercq C, Rex S, Garrigue S, Lavergne T, Cazeau S, et al. Long-term benefits of biventricular pacing in congestive heart failure: results from the MUltisite STimulation in cardiomyopathy (MUSTIC) study. J Am Coll Cardiol. 2002;40(1):111-8.

38. Cleland JG, Daubert IC, Erdmann E, Freemantle N, Gras D, Kappenberger L, et al. The effect of cardiac resynchronization on morbidity and mortality in heart failure. $N$ Engl J Med. 2005;352(15):1539-49.

39. Auricchio A, Stellbrink C, Sack S, Block M, Vogt J, Bakker P, et al. Pacing Therapies in Congestive Heart Failure (PATH-CHF) Study Group. Long-term clinical effect of hemodynamically optimized cardiac resynchronization therapy in patients with heart failure and ventricular conduction delay. J Am Coll Cardiol. 2002;39(12):2026-33.

40. Bristow MR, Feldman AM, Saxon LA. Heart failure management using implantable devices for ventricular resynchronization: Comparison of Medical Therapy, Pacing, and Defibrillation in Chronic Heart Failure (COMPANION) trial. COMPANION Steering Committee and COMPANION Clinical Investigators. J Card Fail. 2000;6(3):276-85.

41. Young JB, Abraham WT, Smith AL, Leon AR, Lieberman R, Wilkoff $\mathrm{B}$, et al. Combined cardiac resynchronization and implantable cardioversion defibrillation in advanced chronic heart failure: the MIRACLE ICD Trial.JAMA. 2003;289(20):2685-94.

42. Epstein AE, DiMarco JP, Ellenbogen KA, Estes NA, 3rd, Freedman RA, Gettes LS, et al. ACC/AHA/HRS 2008 Guidelines for DeviceBased Therapy of Cardiac Rhythm Abnormalities: a report of the American College of Cardiology/American Heart Association Task Force on Practice Guidelines (Writing Committee to Revise the ACC/AHA/NASPE 2002 Guideline Update for Implantation of Cardiac Pacemakers and Antiarrhythmia Devices): developed in collaboration with the American Association for Thoracic Surgery and Society of Thoracic Surgeons. Circulation. 2008;117(21):e350-408.

43. Strickberger SA, Conti J, Daoud EG, Havranek E, Mehra MR, Pina IL, et al. Patient selection for cardiac resynchronization therapy: from the Council on Clinical Cardiology Subcommittee on Electrocardiography and Arrhythmias and the Quality of Care and Outcomes Research Interdisciplinary Working Group, in collaboration with the Heart Rhythm Society. Circulation. 2005;111(16):2146-50.

44. Mansour M, Reddy VY, Singh J, Mela T, Rasche V, Ruskin J. Threedimensional reconstruction of the coronary sinus using rotational angiography. J Cardiovasc Electrophysiol. 2005;16(6):675-6.

45. Sogaard P, Egeblad H, Pedersen AK, Kim WY, Kristensen BO, Hansen PS, et al. Sequential versus simultaneous biventricular resynchronization for severe heart failure: evaluation by tissue Doppler imaging. Circulation. 2002;106(16):2078-84.

46. Abraham WT, Leon AR, Hannon C. Results of the InSync Marquis clinical trial. Heart Rhythm Journal. 2005;2(5 suppl):S65.

47. Daoud EG, Kalbfleisch SI, Hummel JD, Weiss R, Augustini RS, Duff $\mathrm{SB}$, et al. Implantation techniques and chronic lead parameters of biventricular pacing dual-chamber defibrillators. J Cardiovasc Electrophysiol. 2002;13(10):964-70.

48. McAlister FA, Stewart S, Ferrua S, McMurray JJ. Multidisciplinary strategies for the management of heart failure patients at high risk for admission: a systematic review of randomized trials. J Am Coll Cardiol. 2004;44(4):810-9.

49. Hunt SA, Abraham WT, Chin MH, Feldman AM, Francis GS, Ga- 
niats TG, et al.2009 Focused update incorporated into the ACC AHA 2005 Guidelines for the Diagnosis and Management of Heart Failure in Adults A Report of the American College of Cardiology Foundation/American Heart Association Task Force on Practice Guidelines Developed in Collaboration With the International Society for Heart and Lung Transplantation. J Am Coll Cardiol. 2009;53(15):e1-e90.

50. Spragg DR, Berger R, Kass D, Calkins H. Textbook of Cardiovascular Medicine. Philadelphia: LWW; 2007 [updated 2007; cited];
3rd:|Available from: http:/|books.google.com/books?id=35zSLW yEWbcC\&printsec=frontcover\&dq=Textbook + of + Cardiovascula r+Medicine,3rd+ed\&hl=en\&sa=X\&ei=aNBMT-7nBeTf4QTwr7noA g\&ved $=0$ CDEQ6AEwAA\#v=onepage \&q=Textbook\% 20 of $\% 20 \mathrm{Car}-$ diovascular\%20Medicine\%2C3rd\%20ed\&f=false.

51. Curtis JP, Luebbert JJ, Wang Y, Rathore SS, Chen J, Heidenreich PA, et al. Association of physician certification and outcomes among patients receiving an implantable cardioverter-defibrillator. JAMA. 2009;301(16):1661-70. 